\title{
Experimental Bin Drenching System for Testing Biocontrol Agents to Control Postharvest Decay of Apples
}

\author{
W. J. Janisiewicz and D. L. Peterson, USDA-ARS, AFRS, Kearneysville, WV; K. S. Yoder, VPI\&SU, Winchester, \\ VA; and S. S. Miller, USDA-ARS, AFRS, Kearneysville, WV
}

\begin{abstract}
Janisiewicz, W. J., Peterson, D. L., Yoder, K. S., and Miller, S. S. 2005. Experimental bin drenching system for testing biocontrol agents to control postharvest decay of apples. Plant Dis. 89:487-490.

A portable drencher capable of drenching a single bin of fruit was built to simulate the commercial application of chemicals to harvested apples in small orchard operations in the central and eastern United States. The drencher required as little as 125 liters of the treatment solution and permitted various bin travel speeds. Wounded apples were placed midway between the bottom and top of the bin, in the center, and near the four corners of the bin (20 fruit per location) and covered with enough unwounded apples to fill the bin. The bins were drenched with a suspension containing Penicillium expansum at $2 \times 10^{4}$ conidia per $\mathrm{ml}$ in $2000,5 \times 10^{3}$ conidia per $\mathrm{ml}$ in 2001, and $3 \times 10^{3}$ conidia per $\mathrm{ml}$ in 2002 and 2003. In 2000 and 2003, the additional treatments included a combination of P. expansum with the yeast Metschnikowia pulcherrima at $\sim 1.2$ $\times 10^{7} \mathrm{CFU} / \mathrm{ml}$, and in 2003 a combination with $2 \%$ sodium bicarbonate (SB) or a mixture of the yeast and SB. After 3 months of storage at $\sim 2^{\circ} \mathrm{C}$, at all P. expansum conidial concentrations, more than $90 \%$ of wounded fruit developed decay on 'Golden Delicious', 'Delicious', and 'Rome' apples in the 2000-02 experiments. In 2003, 66 and $33.1 \%$ of the wounded fruit developed decay on 'Delicious' and 'Golden Delicious', respectively. The application of the antagonist reduced decay to 39 and 3.3\% on 'Golden Delicious' in 2000 and 2003, respectively, and to $26 \%$ on 'Delicious' in 2003. The addition of SB reduced decay on both cultivars and, in combination with the yeast, was the most effective treatment on 'Golden Delicious'. This portable drencher can be very useful for evaluating different treatments applied to apples after harvest at the commercial level.
\end{abstract}

Additional keywords: blue mold, Malus $\times$ domestica, pome fruits

After harvest and before being placed in storage, most apples are drenched with diphenylamine (DPA) to control superficial scald, a physiological disorder $(10,11)$. Drenching may be applied to whole truck or trailer loads of bins with fruit or to a few bins at a time in smaller orchard operations. The drenching suspension is recirculated to treat additional bins. During this process, conidia of fungi causing fruit decay are washed from the surface of fruit, bins, and soil carried at the bottom of the

Corresponding author: W. J. Janisiewicz

E-mail:wjanisie@afrs.ars.usda.gov

Mention of trade names or commercial products in this publication is solely for the purpose of providing specific information and does not imply recommendation or endorsement by the U.S. Department of Agriculture.

* The $\boldsymbol{e}$-Xtra logo stands for "electronic extra" and indicates that Figures 2 and 3 appear in color in the online edition.

Accepted for publication 20 December 2004

DOI: 10.1094/PD-89-0487

This article is in the public domain and not copyrightable. It may be freely reprinted with customary crediting of the source. The American Phytopathological Society, 2005. bins and accumulate in the drenching suspension (17). Most of these pathogens are necrotrophs, such as Penicillium expansum and Botrytis cinerea, and infect fruit mainly through wounds made during and after harvest. The drenching suspension must be supplemented with fungicides to protect fruit against postharvest decays caused by these fungi $(11,18)$. However, there are a variety of limitations to the use of fungicides on harvested fruit, and in some countries postharvest fungicide treatment has been banned (4).

Alternatives to synthetic fungicides have been explored continually during the past decade, and biological control of postharvest diseases of fruit has emerged as one of the most effective methods. In recent years, two commercial products, Aspire (Ecogen-Israel Partnership, LTD) and BioSave (JET Harvest Solutions, Orlando, FL), have been registered in the United States, and two more, Avogreen and Yield Plus, are registered abroad (6). On pome fruits, the biocontrol agents have been applied mainly in large packinghouses by dipping or spraying fruit during sorting and before packing and by drenching during presizing (L. Grant, personal communication). The method of application has a significant influence on the efficacy of the biocontrol agents. For example, spray applications are more effective than drenching because the spray is usually applied as fruit pass over a series of rotating soft brushes on the packing lines. This results in rapid rotation of fruit and improved coverage with biocontrol agents (L. Grant, personal communication, W. J. Janisiewicz, personal observation). Spray or dip applications of the biocontrol agents have been evaluated often in the past $(5,7)$, but bin drenching applications have been limited to pilot tests with the final commercial formulation of the antagonist and natural pathogen inoculum $(2,9,13)$. This is primarily due to the large scale of these tests, which require not only large amounts of fruit but also a considerable volume of treatment suspension. Laboratory production of the biocontrol agents for large-scale application is financially and technically prohibitive for most laboratories, especially if numerous treatments or combinations of treatments are to be tested. But these kinds of tests are necessary for selecting the most effective biocontrol agents for drench applications.

Sodium bicarbonate (SB) is a GRAS (generally recognized as safe) substance that is exempt from residue tolerance by the U.S. Environmental Protection Agency (EPA) and can be applied to all fruits and vegetables. The use of sodium bicarbonate alone to control postharvest decays of fruit has its limitations (12), but it can be combined with other alternative treatments to synthetic fungicides, resulting in control that is superior to the individual treatments alone. For example, SB has been successfully used in combination with bacterial and yeasts biocontrol agents to enhance control of postharvest decays on citrus, pome, and stone fruits $(15,19)$.

In this paper, we report on the development of a portable drencher capable of drenching one bin of fruit at a time using a low volume of treatment suspension for evaluating the efficacy of antagonist and chemical treatments in controlling fruit decay under commercial conditions.

\section{MATERIALS AND METHODS}

Drencher design. A steel framework was constructed to support the components of the drencher (Fig. 1). The frame supported two $0.45 \mathrm{~m}$ wide by $2.65 \mathrm{~m}$ long roller conveyor panels (Figs. 1 and 2) that supported a standard fruit bin and allowed the bin to be easily pushed through the 
drenching area. Two parallel drive chains with attached push panels (one on either side of the bin) were used to move the bin along the roller panels and under the dispensing reservoir. The chains were driven by a DC motor with a variable speed/reversible control unit (Models 108230 and 174308; Leeson Electric Corp., Grafton, WI). Limit switches at both ends of the drencher were engaged by the push panels to stop the movement of the bin at the edge of the unit. The dispensing reservoir was a 1.2-m-long, 114-mm outside diameter PVC pipe (4 inch schedule 40) with a row of outlet holes positioned at the lowest point on the pipe. There were 94 outlet holes, $6.35 \mathrm{~mm}$ in diameter and spaced at $12.7-\mathrm{mm}$ intervals. One end of the dispensing reservoir was vented to the atmosphere and the other end

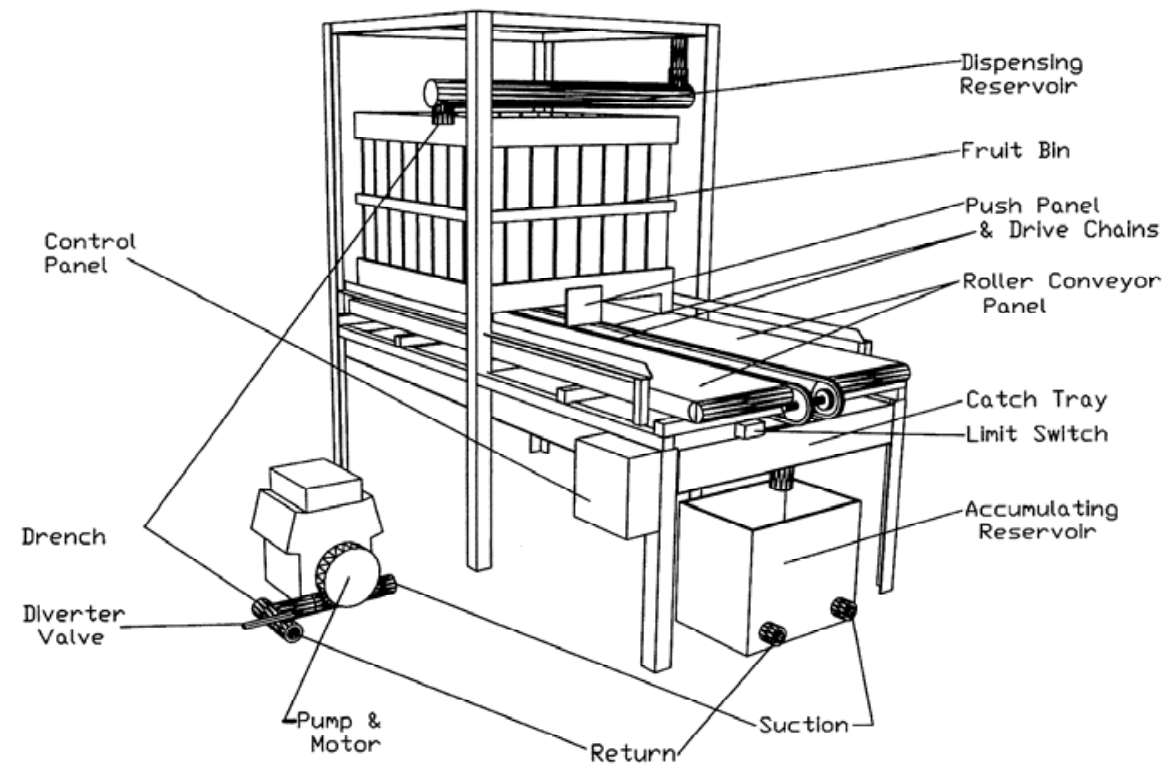

Fig. 1. Schematic of the bin drencher. The steel frame supported two long roller conveyor panels to facilitate bin travel through the drenching area. The dispensing pipe reservoir was connected by hose to a diaphragm pump that supplied the drenching fluid from the accumulating reservoir. The pump could send fluid to either the dispensing reservoir or the accumulating reservoir. After fruit drenching, the fluid was collected by a catching tray with an outlet to the accumulating reservoir.

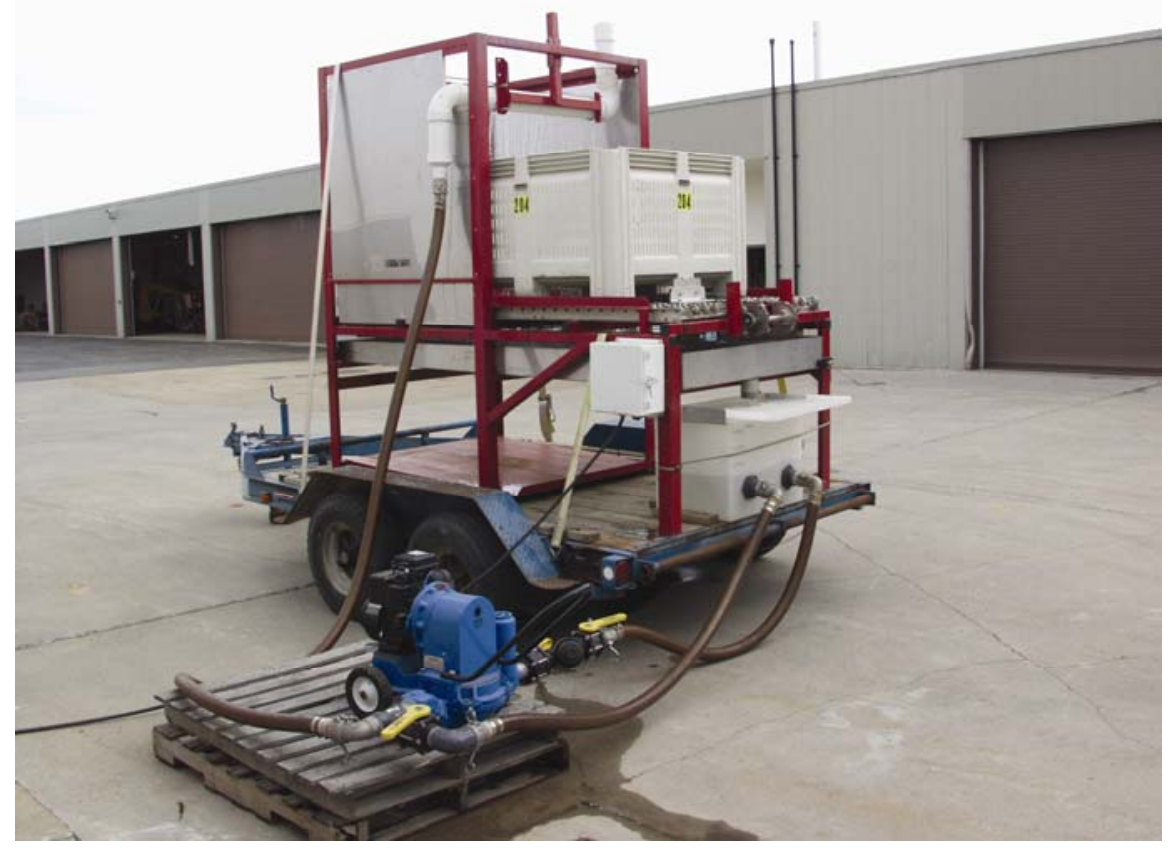

Fig. 2. Drenching bin of fruit. After positioning a bin with fruit onto the roller conveyor panels using a forklift, the pump was activated to start the drench curtain, and the automated system was activated for bin travel through the drench curtain. After the bin passed through the curtain, fluid was diverted from the pump back to the accumulating reservoir, and the direction of bin travel was reversed to its starting position. connected to a 50-mm-diameter hose. This hose was also connected to a diaphragm pump (Model 2ADG3-1; Barnes Pumps, Inc., Piqua, $\mathrm{OH})$ that supplied the drenching fluid. The pump's suction line was connected to a 150-liter capacity accumulating reservoir. At the outlet of the pump was a diverter valve that can send fluid to either the dispensing reservoir or back to the accumulating reservoir. The gasoline motor driven pump operated at 85 liters/min. Fluid leaving the outlet holes in the dispensing reservoir passed through the fruit bin and was collected by a stainless steel catching tray. The bottom of the catching tray was sloped toward the front of the drencher. An outlet in the catching tray allowed the fluid to be recycled to the accumulating reservoir. With the original design tested in 2000, the fluids passing through the bin were caught in a plastic container with a sloped bottom to reduce volume. Due to the loss of drenching suspension from splashing with this design, the catching tray and the accumulating reservoir were added in 2001. The cost of all materials required for building the drencher was $\$ 7,200$, and the labor was approximately $150 \mathrm{~h}$.

Drencher operation. A forklift was used to position a bin of fruit onto the roller conveyor panels (Fig. 2). The diaphragm pump was activated to fill the dispensing reservoir and start the drench curtain. At the control panel, a switch was activated to start the movement of the bin toward the drench curtain. Speed of bin movement was previously set to the desired rate. When the bin had completely traveled past the drench curtain, the bin stopped and the drenching fluid was diverted back to the accumulating reservoir. Then the direction of the bin movement was reversed to return the bin to its starting position, and the bin was removed by forklift.

Pathogen and antagonist. The isolate of $P$. expansum (MD-8) used to test the experimental drencher was a very aggressive isolate previously used in various biocontrol tests $(5,7)$. MD- 8 was originally isolated from a decayed apple and was maintained on potato dextrose agar (PDA) with periodic transfers through apple to assure continued virulence. The conidial suspensions used for fruit inoculations were prepared from 10-day-old cultures as previously described (7). The conidial suspension was prepared as concentrated stock, which, when added to 125 liters of water in the drencher tank, resulted in a final concentration of $2 \times 10^{4}$ conidia per $\mathrm{ml}$ in $2000,5 \times 10^{3}$ conidia per $\mathrm{ml}$ in 2001 , and $3 \times 10^{3}$ conidia per $\mathrm{ml}$ in 2002 and 2003.

The antagonist used was the yeast Metschnikowia pulcherrima strain FMB$24 \mathrm{H}-2$, isolated from wounded apples and capable of growing at cold temperatures (8). The yeast was grown in $200 \mathrm{ml}$ of 
nutrient yeast dextrose broth (NYDB) medium in 500-ml Erlenmeyer flasks on a rotary shaker at $200 \mathrm{rpm}$ at $26^{\circ} \mathrm{C}$ for $24 \mathrm{~h}$. The cells were then harvested by centrifugation at $7,000 \times g$ for $10 \mathrm{~min}$, and the pellet was collected and stored in $50-\mathrm{ml}$ tubes at $4^{\circ} \mathrm{C}$. The yeast was produced over 6 days. On the seventh day, an appropriate weight of the fresh cell preparation (according to the standard curves developed for fresh yeast cell preparations) was resuspended in 1 liter of water to make a concentrated stock suspension, which after adding to the drench tank with 125 liters of water, resulted in yeast cell concentration of $\sim 1.2 \times 10^{7}$ cells per $\mathrm{ml}$.

Sodium bicarbonate. Sodium bicarbonate (SB) was purchased in a local grocery store as Pure Baking Soda (Arm \& Hammer, Division of Church \& Dwight Co., Inc., Princeton, NJ) and was used at a concentration of $2 \%(\mathrm{wt} / \mathrm{vol})$. The appropriate amount of SB was added to the drench tank, and the suspension was circulated, first in the tank by closing the valve leading to the drenching pipe for $5 \mathrm{~min}$, and then through the drencher by opening the valve for another $5 \mathrm{~min}$.

Fruit. Apples were harvested when a majority of the fruit in the test cultivar reached a commercially acceptable stage of maturity for regular cold storage based on flesh firmness, soluble solids concentration, and starch index (SI) rating. Ten apples were harvested at random, and flesh firmness was measured on opposite sides of each fruit with a penetrometer (Model FT-327; McCormick Fruit Tech, Yakima, WA) fitted with an 11.1-mm tip and mounted in a drill press stand. Soluble solids concentration was determined with a digital refractometer (Atago PR100; NSG Precision Cells, Inc., Farmingdale, NY) from a composite juice sample from the 10-apple sample. The starch-iodine index was visually rated using the technique described by Blanpied and Silsby (1). Apples were considered acceptable for harvest when the average starch index rating fell within the range of 3 to 5 on the Cornell Generic SI chart (1). The fruit were harvested into standard fruit bins, each holding about $400 \mathrm{~kg}$ of apples, which corresponds to approximately 2,000 apples per bin.

Fruit drenching and storage. To test the experimental drencher, bins with fruit were half-emptied, and 100 fruit wounded with a 6-penny nail $3 \mathrm{~mm}$ deep were placed midway between the bottom and top of the bin in the center and near the four corners (20 fruit in each location) and covered with apples to fill the bin. A thin bird netting (eye $1 \mathrm{in}^{2}$ ) was placed below and over the wounded fruit to facilitate easy separation of the wounded fruit from the rest of the fruit for evaluation of decay incidence after storage. The bins were drenched within $2 \mathrm{~h}$ after wounding using the portable drencher with a suspension containing $P$. expansum alone or in combination with the antagonist, sodium bicarbonate (SB), or a mixture of the two. SB treatment was used only in 2003. The travel time of a bin through the drencher was $1 \mathrm{~min} 50 \mathrm{~s}$. During that time, 157 liters of drenching suspension passed through the bin. After treatment application, the drencher and hoses were emptied, washed with water, sterilized with $70 \%$ ethanol, and washed again in water before application of the next treatment. There were three bins of apples per treatment, and each bin constituted a single replicate. Bins with treated fruit were placed in regular refrigerated cold storage at $\sim 2{ }^{\circ} \mathrm{C}$, and wounded fruit were evaluated for decay incidence after 3 months. The fruit from different cultivars were treated at different times at least 1 week apart. For each cultivar, the inoculum was prepared separately, the antagonist from new liquid cultures, and the pathogen from new culture plates.

Statistical analysis. Results from the 2003 experiment were analyzed using the general linear model (GLM) of the Statistical Analysis System (SAS v. 8.2, SAS Institute Inc., Cary, NC) with pathogen alone or in combination with antagonist, $\mathrm{SB}$, and mixture of both as well as position of fruit in the bin (center or corner) as treatment variables and incidence of decay as a response variable. A Waller-Duncan multiple range test $(k$-ratio $=100)$ was conducted to separate means of the fruit decay data for each cultivar and for the position of fruit in the bins for individual treatments in 2003.

\section{RESULTS AND DISCUSSION}

The drencher design allowed for application of a treatment to all three bins (replications) without the need for replenishing the suspension. In fact, up to six bins could be treated with the tank reservoir filled to 150 liters. The wounded fruit in the center and four corners were well covered with the drenching suspension, as indicated by the fact that the incidence of decay on wounded fruit was high and relatively uniform regardless of fruit position (Fig. $3)$. There was no significant effect $(P=$ 0.5616 ) of fruit position in the bin on decay development on 'Golden Delicious' in any of the treatments and no effect $(P=$ $0.05)$ in the control and the antagonist treatment on 'Delicious' in the 2003 experiment. Only on 'Delicious' apples in antagonist and SB treatments, fruits in two corners (45 and $36.7 \%$ decay) and in one corner (50\% decay), respectively, had significantly $(P=0.05)$ more decay.

Drenching with $P$. expansum at concentrations of $2 \times 10^{4}$ and $5 \times 10^{3}$ conidia per $\mathrm{ml}$ in 2000 and 2001, respectively, resulted in decay development on more than $97 \%$ of the wounded fruit of 'Golden Delicious' and 'Rome' in both years (Table 1). The decay incidence was reduced from 99 to $39 \%$ by application of $M$. pulcherrima on 'Golden Delicious' apples in 2000 (data not shown). A high decay incidence in $P$. expansum-inoculated fruit indicates that the system was overwhelmed by the pathogen concentration. Thus, for the experiments in 2002 and 2003, concentration of the pathogen was lowered to $3 \times 10^{3}$ conidia per $\mathrm{ml}$. This resulted in a decay incidence of 94.7 and $90.7 \%$ on 'Golden

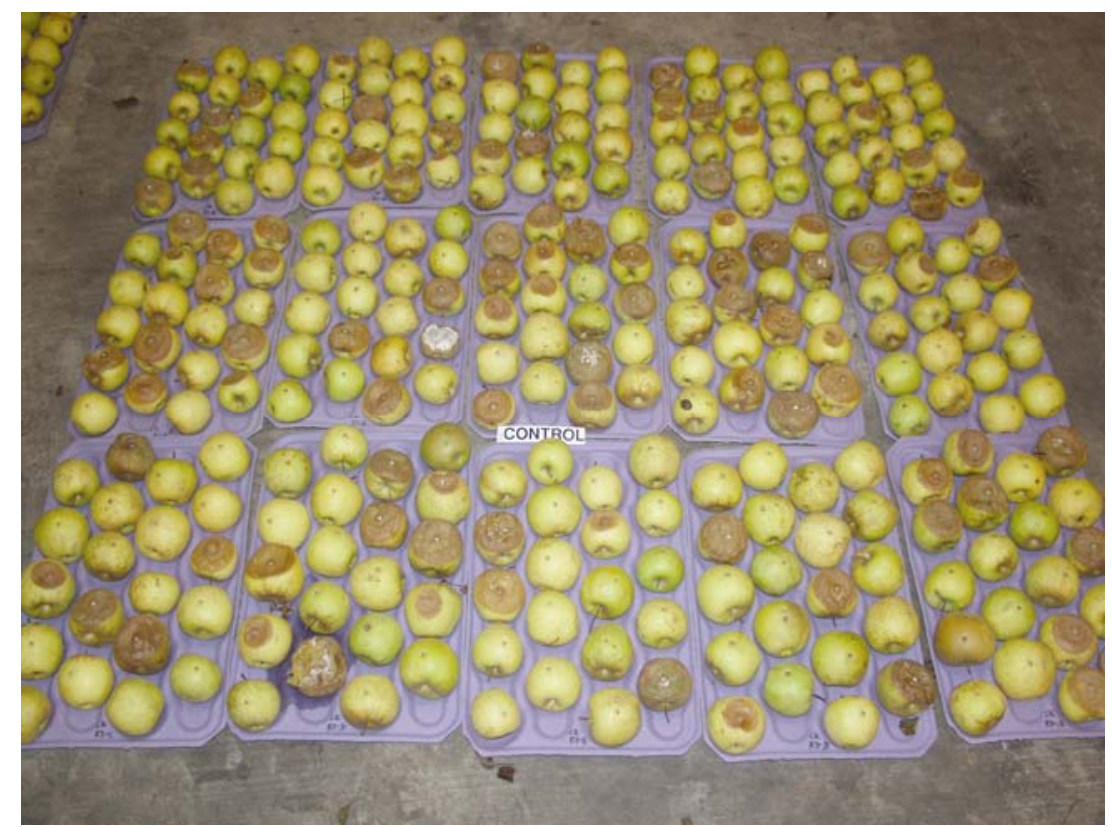

Fig. 3. Wounded 'Golden Delicious' apples inoculated with Penicillium expansum conidia using a drencher apparatus and stored in regular refrigerated cold storage at $\sim 2^{\circ} \mathrm{C}$ for 3 months in 2003 . In each row are five trays from the individual replications (bins). Fruit on the middle tray were removed from the center of the bin, fruit on the remaining trays from the four corners. Note uniform inoculation throughout the trays within a bin. 
Table 1. Decay incidence on wounded apples placed inside bins filled with unwounded apples, drenched with suspensions containing various concentrations of Penicillium expansum conidia, and stored in regular refrigerated cold storage for 3 months at $\sim 2^{\circ} \mathrm{C}$

\begin{tabular}{lcccc}
\hline & & \multicolumn{3}{c}{ Incidence of decay (\%) } \\
\cline { 3 - 5 } Treatment & Year & 'Golden Delicious' & 'Delicious' & 'Rome' \\
\hline $\begin{array}{l}P . \text { expansum } \\
\left(2 \times 10^{4} \text { conidia per } \mathrm{ml}\right)\end{array}$ & 2000 & 99.2 & $\mathrm{NT}$ & 98.7 \\
$\begin{array}{l}P . \text { expansum } \\
\left(5 \times 10^{3} \text { conidia per } \mathrm{ml}\right)\end{array}$ & 2001 & 99.0 & $\mathrm{NT}$ & 97.2 \\
$\begin{array}{l}P \text { expansum } \\
\left(3 \times 10^{3} \text { conidia per } \mathrm{ml}\right)\end{array}$ & 2002 & 94.7 & 90.7 & $\mathrm{NT}$ \\
\hline
\end{tabular}

Table 2. Decay incidence on wounded apples placed inside bins filled with unwounded apples, drenched with various suspensions containing Penicillium expansum conidia alone (control) or combined with the antagonist Metschnikowia pulcherrima and/or sodium bicarbonate (SB), and stored in regular refrigerated cold storage for 3 months at $\sim 2^{\circ} \mathrm{C}$ in 2003

\begin{tabular}{lcc}
\hline & \multicolumn{2}{c}{ Decay incidence (\%) } \\
\cline { 2 - 3 } Treatment & 'Delicious'y & $\begin{array}{c}\text { 'Golden } \\
\text { Delicious' }\end{array}$ \\
\hline Control & $66.0 \mathrm{a}^{\mathrm{z}}$ & $33.1 \mathrm{a}$ \\
Sodium bicarbonate & $34.0 \mathrm{~b}$ & $2.7 \mathrm{~b}$ \\
M. pulcherrima & $26.0 \mathrm{c}$ & $3.3 \mathrm{~b}$ \\
M. pulcherrima $+\mathrm{SB}$ & $8.8 \mathrm{~d}$ & $0.7 \mathrm{~b}$ \\
\hline
\end{tabular}

y 'Delicious' apples were harvested on 1 October and 'Golden Delicious' apples on 24 September. Apples were treated within $24 \mathrm{~h}$ after harvest.

${ }^{\mathrm{z}}$ Means with the same letters within columns are not significantly different according to Waller-Duncan multiple range test $(k$-ratio $=$ 100).

Delicious' and 'Delicious', respectively, in 2002 (Table 1), and 33.1 and $66 \%$ in 2003 (Table 2). The low incidence of decay in 2003 may have resulted from the greater resistance of the apple to blue mold decay that year compared with 2002. Although fruit were picked at a similar stage of maturity to minimize variation in susceptibility to decay among years, the resistance may also be affected by environmental factors and fertilization regimes $(3,14)$. The inoculum concentration in 2002 and 2003 tests corresponded to the highest level of contamination found in dumptanks and drench solutions under commercial conditions $(16,17)$.

Treatment of apples with the yeast $M$. pulcherrima or SB significantly reduced decay on 'Golden Delicious' and 'Delicious' fruit in 2003 (Table 2). The combination of these two treatments was more effective than either treatment alone on 'Delicious' apples. This additive effect was not as evident on 'Golden Delicious' fruit, where the combination of the two treatments had the lowest incidence of decay, but it was statistically not significantly different from the individual treatments. All decay control treatments were very effective on 'Golden Delicious' apples, resulting in $\leq 3.3 \%$ incidence of decay, which may have contributed to the lack of differences between the combination and the individual treatments. Results from our large-scale drenching experiments are in agreement with earlier reports on the beneficial effect of combining SB with bacterial and yeast antagonists to reduce postharvest decay on apples, peaches, and citrus fruits $(15,19)$.

We demonstrated that this drencher is an excellent tool for efficient testing of many decay control measures, including biological control agents under simulated commercial conditions. This drencher could also be used for efficient application of decay control products in small orchard operations where a relatively small number of bins is harvested each day. The low volume of the system will allow for complete replacement of the drenching suspension every day at minimal additional cost. The size of the collection tank could be easily adapted to the number of bins being drenched each day to avoid frequent replenishing of the drenching suspension during the day and at the same time minimizing the amount of suspension remaining at the end of the day.

\section{ACKNOWLEDGMENTS}

We thank S. Wolford for building and help in designing the drencher, and $\mathrm{M}$. Miller and C. Walters for technical assistance in drenching, assessing fruit decay, and collecting the data.

\section{LITERATURE CITED}

1. Blanpied, G. D., and Silsby, K. L. 1992. Predicting harvest date windows for apples. Cornell Coop. Ext. Bull. 221.

2. Droby, S., Cohen, L., Daus, A., Weiss, B., Horev, B., Chalutz, E., Katz, H., Keren-Tzur, M., and Shachnai, A. 1998. Commercial testing of Aspire: A yeast preparation for the biological control of postharvest decay of citrus. Biol. Control 12:97-101.

3. Fallahi, E., Conway, W. S., Hickey, K. D., and Sams, C. E. 1997. The role of calcium and nitrogen in postharvest quality and disease resis- tance in apples. HortScience 32:831-835.

4. Gullino, M. L., and Kuijpers, L. A. M. 1994 Social and political implications of managing plant diseases with restricted fungicides in Europe. Annu. Rev. Phytopathol. 32:559-579.

5. Janisiewicz, W. J., and Jeffers, S. N. 1997. Efficacy of commercial formulation of two biofungicides for control of blue mold and gray mold of apples in cold storage. Crop Prot. 16:629-633

6. Janisiewicz, W. J., and Korsten, L. 2002. Biological control of postharvest diseases of fruits. Annu. Rev. Phytopathol. 40:411-441.

7. Janisiewicz, W. J., and Marchi, A. 1992. Control of storage rots on various pear cultivars with a saprophytic strain of Pseudomonas syringae. Plant Dis. 76:555-560.

8. Janisiewicz, W. J., Tworkoski, T. J., and Kurtzman, C. P. 2001. Biocontrol potential of Metchnikowia pulcherrima strains against blue mold of apple. Phytopathology 91:1098-1108.

9. Jeffers, S. N., and Hankinson, T. R. 1995 Biological control of postharvest diseases of apples and pears: Preliminary results from the 1994 Bio-Save field trial program. Proc. Annu. Wash. Tree Fruit Postharv. Conf. 11th. pp. 3740 .

10. Kupferman, E. M. 1997. Observations on storage regimes for apples and pears. Tree Fruit Postharv. J. 8(3):3-5.

11. Kupferman, E. M., and Gurtzwiler, J. 2002. Effects of DPA drenching on newer apple varieties. Tree Fruit Research and Extension Center, Washington State University. Online publication/EMK2002C.pdf.

12. Palou, L., Smilanick, J. L., Usall, J., and Vinas, I. 2001. Control of postharvest blue and green molds of oranges by hot water, sodium carbonate, and sodium bicarbonate. Plant Dis. 85:371-376.

13. Rosenberger, D. A., Ellerbogen, M. C., EngleAhlers, C. A., Woelfersheim, A., and Meyer, F. M. 1999. Comparison of Decco I-182 (Candida oleophilia) and other postharvest treatments in a commercial apple storage, 1997-98. Biol. Cultural Tests 14:39-40.

14. Sharples, R. O. 1984. The influence of preharvest conditions on the quality of stored fruit. Acta Hortic. 157:93-104.

15. Smilanick, J. L., Margosan, D. A., Mlikota, F., Usall, J., and Michael, I. F. 1999. Control of citrus green mold by carbonate and bicarbonate salts and the influence of commercial postharvest practices on their efficacy. Plant Dis. 83:139-145

16. Spotts, R. A., and Cervantes, L. A. 1986 Populations, pathogenicity, and benomyl resistance of Botrytis spp., Penicillium spp., and Mucor piriformis in packinghouses. Plant Dis. 70:106-108.

17. Spotts, R. A., and Cervantes, L. A. 1993. Filtration to remove spores of Penicillium expansum from water in pome fruit packinghouses. Tree Fruit Postharv. J. 4(1):16-18.

18. Willett, M., and Kupferman, E. M. 1991. Management practices to minimize postharvest decay of apple and pear. Tree Fruit Postharv. J. 2(2):5-8.

19. Wisniewski, M., Wilson, C., El Ghaouth, A., and Droby, S. 2001. Increasing the ability of the biocontrol product, Aspire, to control postharvest diseases of apple and peach with the use of additives. Biological Control of Fungal and Bacterial Plant Pathogens, IOBC wprs Bull. 24(3):157-160. 